\title{
Physics Experiments Planned by The Students Themselves - Higher Secondary Education
}

\author{
Peter Demkanin ${ }^{a}$, Milan Kováč ${ }^{b}$ \\ ${ }^{\mathrm{a}, \mathrm{b}}$ Comenius University in Bratislava, Faculty of Mathematics, Physics and Informatics, Bratislava, \\ Slovakia, demkanin@fmph.uniba.sk
}

\begin{abstract}
More than 15 years ago we started to implement in our physics curriculum for 17 years old pupils physics experiments planned by students themselves. Each student must learn, how to prepare and perform a physics experiment. The leading idea of this endeavor is "student must do, what she/he wants, at least sometimes". As a most problematic part of this task is, as has been proved, to teach students to formulate a problem - a question, which can be answered by an experiment and also to formulate a hypothesis, a prediction based on the previous knowledge or based on the information gathered from secondary sources. As important we also see the connection of planning experiments to the goals and aims of science education and sensibility of it from the view of pupils and their parents. Planning experiments by students themselves is a task involving a manifold cluster of means of knowledge gathering and utilization. As generally in creativity, the crucial role has memory. The student applies his/her knowledge. But, at the same time, he/she learns, what is the optimal, useful strategy and structure of working, optimal management for a teamwork. Within planning, a student flips through external sources of information, usually, electronic sources or textbooks, focus his/her attention to information interesting or potentially useful for the phenomenon examined by the experiment just planned. Student remembers, what equipment is available, looks for other equipment and material. Of course, the student also learns to write scientifically, to write in a manner, that nothing hampers understanding of the focus, process, and outcomes. Part of the article is devoted to the topic of development abilities of pre-service physics teacher's to scaffold the process of planning experiments of their future students.
\end{abstract}

Keywords: physics education, open inquiry, planning; school science experiment 


\section{Introduction}

This contribution aims to present our experience with physics experiments prepared by adolescents within formal physics education at higher secondary education. The main idea of our work presented is ,the students must do, what they want, at least sometimes“. Our intention is not to go the way, in which all (or majority of) work is directed by students. The opposite is the truth. We are presenting programme with firm, clearly stated aims and goals, where students are quite firmly lead to the development of their competencies, abilities, and where aspects for measurement of outputs, as well as summative assessment rubrics, are clearly set. The work presents out endeavour from the last 15 years. We have started by our knowledge gained mainly empirically and by the rules for Assessment of practical work in Physics set by International Baccalaureate Diploma programme. The three domains of theoretical grounds we are presenting here we have adopted only a few years ago - as can be seen by the data when the theories were published.

One of our theoretical groundwork is Knowledge in Pieces and primitive phenomenologies (p-prims) approach by di Sessa (2014). While original KiP approach focuses on the concepts as buoyancy, Archimedes principle, or electromotive force of a battery, electric resistance or electric current; we deal with concepts related to empirical cognition, like hypothesis, general plan of experiment, operational plan, independent and dependent variable, constants of an experiment, evidence, claims. Within the conceptual change, we try to avoid the typical diachronic models based on the naive state on one hand and the normative state on the other. We try to go to a much finer timescale and establish a connection between thinking during learning events and long-time change. We use the term event of learning, where, as a learning, we consider "making sense of a new experience by learners in collaboration with others" (Harlen, 2006). The possibility to utilize such approach to computer modeling is open, but it is not the main goal of the work presented in this article.

The base for the modeling of a conceptual change is a mechanism, how particular entities behave (knowledge ontology). The question is, how and when knowledge entities change or how and when new ones come about. We, as Machamer, Darden and Craver (2000) use a term mechanism sketches, which can help in an analysis of approaches to solving a realworld (at the adolescent level) complex problems. Solutions of such problems, relevant for adolescents, we scaffold by exposing "black boxes" they need filling in. On a grain size level, casual scheme (di Sessa, 2014) is a learner-centered idea what a learner takes as general, explanatory, and predictive about a class of phenomena. Students should be able to state and defend the meaning and plausibility of their scheme and also, after the activity, socially share important aspects of what they have learned. Physical intuition is taken as a 
vocabulary of phenomenological primitives (p-prims) which provide sensibility and naturalness of everyday phenomena. Central position in intuitive physics has competition among dual agencies. Knowledge in Pieces, as a general framework, contains also the assumptions: naive knowledge in physics is rich, complex and diverse; naive conceptual ecology provides rich productive building blocks for understanding, and methodologies: focus on a grain size of knowledge; focus on learning in episodes of few minutes in duration. Within our approach, describing naive pieces of knowledge and p-prims as correct and incorrect is a category error, we even do not use the term misconception, rarely we use pre-conceptions (as a particular net of p-prims connected with particular phenomena).

As we presented in (Demkanin 2018), the process of development of knowledge is quite often regarded as a process from a naive representation towards the normative knowledge, via instructions (Figure 1).

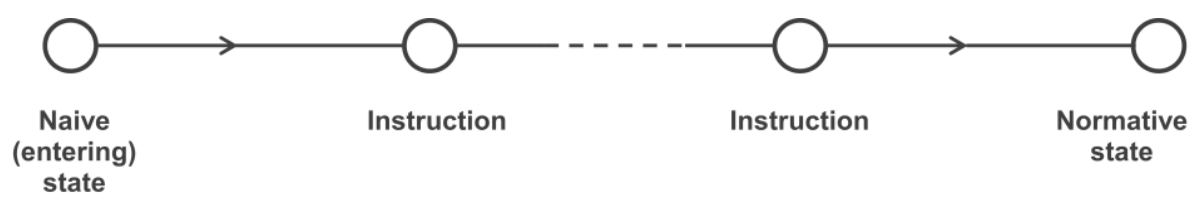

Fig. 1 Usual look at the process from naive to normative representation

In this way, we would like to avoid talking about instructions itself, we would like to focus on pupils' thinking. The information involved in these thinking processes is often gathered empirically. A student gets some empiria about concepts like hypothesis, a general plan of the experiment, operational plan, independent and dependent variable, constants of an experiment, evidence, claims.

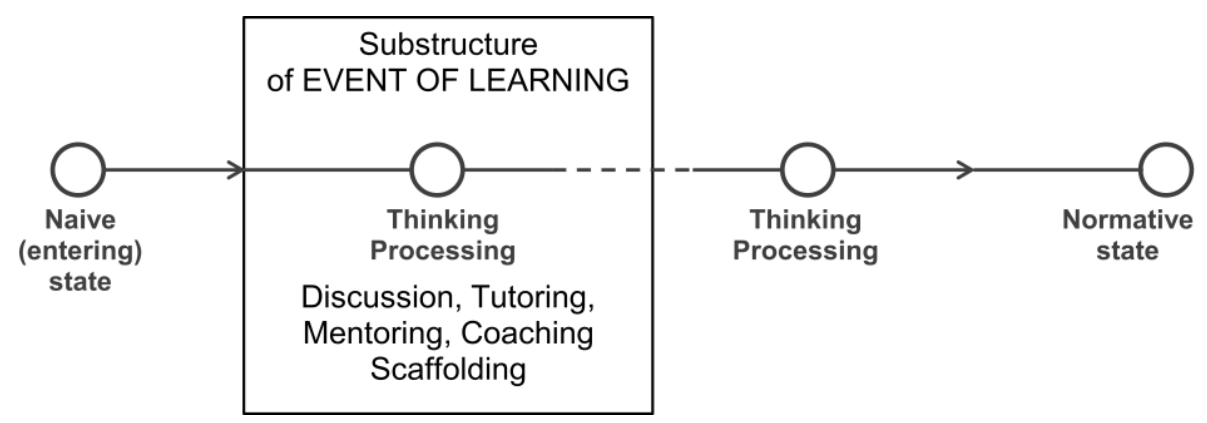

Fig. 2 Process from naive to normative representation in the light of The Learning Science approach 
Even at the naive state, and even in an early childhood each pupil has some experience with words as a prediction, forecast, planning, evidence, statement, claim. It seems profitable to study the substructure of an event of learning deeply. Some results of such deep study are presented in Sawyer (2015) and diSessa (2014). In Figure 2 we also highlighted methods of Physics Education Tutoring, Mentoring, Coaching, and Scaffolding, which well lead to fulfilling the goals of Science education (Demkanin 2018).

The second base of our work is the work of neuroscientists, who clearly prove, that human is a social being. In this article we present the development of a pupil to plan an physics experiment by themselves. Let's look, a little bit deeper, at the word „themselves“. Each student lives in a society, in a community of peers, school community (including teachers and pupils), lives in a family. Neuroscientists, like M. Lieberman, are converging to interesting ideas: "Teachers are losing the education war because our adolescents are distracted by the social world. Naturally, the students don't see it that way. It wasn't their choice to get endless instruction on topics that don't seem relevant to them. They desperately want to learn, but what they want to learn about is their social world - how it works and how they can secure a place in it that will maximize their social rewards and minimize the social pain they feel. Their brains are built to feel these strong social motivations and to use the mentalizing system to help them along. Evolutionarily, the social interest of adolescents is no distraction. Rather, it is the most important thing they can learn well." (Lieberman 2013, p.282). When we discuss the planning of a physics experiment by a student themselves, we mean, that the experiment should not to be planned by a teacher, should not be planned by a peer, should not be taken from a web or a book. This does not contradict the idea, that we can use scaffolding. Teacher or a textbook, instructions can scaffold the independent work of a pupil working in among peers, working in a welldesigned environment. Also, particular competencies, partial abilities related to the planning are developed by other means, including teacher planned experiments and demonstrations. The results, planned (as well as executed, analyzed and discussed) experiments must be socially shared to allow the pupil to get relevant feedback. We know, that one of the important aspects of a creative product is the purpose for the community, for peers. So, the results of such experiment should be presented to peers and peers should present the meaning, the role of it, in their knowledge building.

The third of our base theoretical background is the science of well-being. Clearly, within formal education, we try to develop healthy people, people capable of living in a society, on the Earth. Research in the science of well-being has recently suggested a need to revise outdated traditional concepts of a healthy personality by recognizing the character features that facilitate adaptation to current challenges to the survival of humanity (Cloninger and Kedia, 2011). As we have pointed out (Demkanin, 2003), Science education from the perspective of the majority of science teachers (in many countries) is 
quite stable. But changes in society are relatively fast, and this is true also in the aspects closely related to science education. Information is easily accessible (generally, not from the perspective of pupils), the speed of communication has risen significantly; our pupils use the equipment, which was available only in some top laboratories some years ago. Science education should also reflect great changes in society, like globalization, climatic changes, terrorism, a boom of automotive and building industry; and, in many countries, also radical political changes and economic crisis. (Demkanin, 2013). Similarly, Cloninger (2008), explains, that war, greed, and divisive propaganda dominate the world stage at present despite the remarkable human capacities for compassion, generosity, and selfawareness (Cloninger, 2008). As long as human beings were able to treat the world as an unlimited resource to be consumed indiscriminately, it was sufficient to regard people who were self-directed and cooperative as healthy even if they were also low in selftranscendence (Cloninger and Kedia, 2011). The concept of a well-organized character with low self-transcendence is still the favored social norm in many Western cultures, the organized character has even been proposed as a description of healthy personality in Diagnostic and Statistical Manual of Mental Disorders DSM-5 (Cloninger, 2010), (Demkaninová, 2015). However, as Cloninger (2013) writes, human utilisation of resources has exceeded the capacity of the planet to replenish, and, consequently, the characteristics of healthy people must be revised to recognise the need for people to live sustainably in appreciation of the needs of humanity as a whole and the capacity of the world environment to support those needs. The changing world conditions reveal the crucial advantages that the creative character structure with high self-transcendence has over the organized character with low self-transcendence. Clonninger (2013) asks himself: "Why do intelligent people revert to a state of fear or denial?" And answers: "I suggest that the main reason can be found in the weakness of individuals with organized character profiles, which is the socially favored profile in secular Western cultures. People are born with a natural need for virtues like fairness and equality that is expressed as self-aware consciousness develops. However, in Western cultures social norm-favoring leads to increases in self-directedness and cooperativeness along with decreases in self-transcendence between the ages of 20 and 45 years; self-transcendence only rises again later as people face ultimate situations like their own mortality. Unfortunately, organized characters are not self-transcendent: They are largely motivated by their self-interests and the interests they share with those close to them. As a result, they strive to maintain their own power and wealth regardless of the consequences for others who are remote. They want to believe that their efforts can allow them to maintain the conditions that have brought them success, so they are also easily manipulated by disinformation from others in positions of power and influence." and later in the same article, "The development of self-transcendence has a radical transformative impact on self-directedness and cooperativeness. The purposeful striving of selfdirectedness is transformed into hope and letting go of fighting and worry. The tolerant 
empathy of cooperativeness is transformed into love and working in the service of others. Essentially, an outlook of unity (i.e., the awareness that one is an inseparable component of a universal unity of being) allows a person to function realistically with plasticity and virtue, thereby living in sustainable harmony with nature and other people. Perhaps this is the reason that leadership during periods of the Renaissance and the Enlightenment have been characterized by the creative character rather than the organized characters that have led us into the current crises of civilization."

\section{Realization}

So after these three domains of our theoretical background, let us go to the school physics experiment itself and let us take, as an example, well developed curriculum of the International Baccalaureate Organisation. In the curriculum for the early childhood to the late adolescence, we aim to develop people who strive to be inquirers, knowledgeable, thinkers, communicators, principled, open-minded, caring, risk-takers, balanced, and reflective. Across all programmes share common believes, that "students construct meaning by designing, conducting and reflecting on scientific investigations. The scientific process, which encourage hands-on experience, inquiry, and critical thinking, enable students to make informed and responsible decisions, not only in science but also in other areas of life." (IBO, 2014a, p.5). This means a recognizable shift from the previous version (IBO, 2001), in which requirements for practical investigations are mainly centred on the assessment of practical skills and also different types of experimental work that a student may engage in serve other purposes, including illustrating, teaching and reinforcing theoretical concepts; developing an appreciation of the essential hands-on nature of scientific work; and developing an appreciation of the benefits and limitations of scientific methodology.

Inspired by the ideas mentioned above, we, in 2005 started to implement to the pre-service teacher training ideas of planning experiments, of experiments planned by secondary school students themselves. It seems to be clear, that students can plan experiments which are in a much simpler physics context, that is, what they are just learning. So we decided to focus on the development of skills, not on new concepts. As we have already mentioned in this article, we have changed this pre-assumption and we now regard the concepts related to empirical cognition as new concepts built and developed by activities mentioned later in this article. So, we develop skills and concepts related to empirical cognition and allow students to apply their knowledge in a context, which is not too complex, not too difficult, ideally close to their experience.

We have started by presenting and discussing the aspects of practical work, which is to be developed. We used almost the same aspects, as IB curriculum use, defining a problem and 
research question (identifying and presenting); formulating a hypothesis (or prediction, directly related to the research question, well supported by a working theory, by previous knowledge and knowledge gained from secondary sources during the planning process); selecting dependent variable, independent variable and constants of the experiment; design of apparatus and selecting material; designing a method for control of variables; designing a method for the collection of data.

In the pre-service teacher training, we have developed a set of activities, which contain:

A. Planning experiment, in which the object to be used is given and it is an object of general purpose (fixed by the instructions). Our instruction is just: Plan an experiment in which you will use rubber band and standard school laboratory equipment.

After discussing and evaluating students plans and after performing most of the plans (as demonstrations, trying to perform them precisely as they are planned, including non-sense steps planned or including struggling if parts of the plans are not clear enough), we went to the second activity.

B. Role play planning experiment at the level of lower secondary physics. The lecturer together with two students, each in a role of 14-years pupils, performs experiment investigating the force exerting on a trolley on an incline. Based on the experience and knowledge of 14 years old pupils have stated a hypothesis, that force, necessary to keep the trolley at rest on the incline is directly proportional with the angle of the inclined. This hypothesis was tested and proved (with quite a strong disagreement with other students). Within final discussion we have agreed, that the only mistake in the inquiry was a mistake of the extrapolation (generalization) of the results, The experiment was realized for the range of angles from $0^{\circ}$ to $30^{\circ}$, where the relation within the measurement uncertainty is really a direct proportion.

C. Planning experiment for formal, written formative assessment. The object to be explored is given and it is a simple object well known by students. Students were given a sheet of four briefly mentioned situations/contexts supported by pictures. Cantilever, domino bricks, paper helicopter, ball. Every student chose one and planned experiment exploring one aspect of the context chosen. Students were instructed to hand in their plans and were given a formal written assessment. They were instructed, that this assessment will have no role in their summative assessment, that the assessment serves only as a feedback for their learning.

D. Planning experiment for summative assessment. Open inquiry, planning experiment, in which the object to be used is given and it is an object more special, related to the physics curriculum (fixed by the instructions). Our instruction is just: Plan an experiment, in which you will use any number of neodymium magnets and standard school laboratory equipment. 


\section{Analysis}

The set of activities was realized in the summer terms in 2016 (6 students), 2017 (9 students) and 2018 (9 students). Lab reports were analyzed. In every student we have noticed a notable rise in their abilities related to the planning of experiment, defining a problem and research question (identifying and presenting); formulating a hypothesis (or prediction, directly related to the research question, well supported by a working theory, by a previous knowledge and knowledge gained from a secondary sources during the planning process); selecting dependent variable, independent variable and constants of the experiment; design of apparatus and selecting material; designing a method for a control of variables; designing a method for the collection of data. For each criterion, we used assessment rubrics designed by IBD programme (IBO, 2001). Also, each lab report we analysed against criteria (IBO, 2014): personal engagement (personal significance, interest, curiosity, personal input, initiative, planning of work with and for a team); exploration (epistemic focus, idea generation, activity, knowledge seeking, background information used, relevance, reliability and sufficiency of the information used; awareness of the significant safety, ethical and environmental issues); analysis (planning of information processing); communication (clarity of the presentation of the focus, processes, use of school science terminology).

The main numerical results presenting the raising ability to plan experiment can be presented by comparing the state just before written task (before activity $\mathrm{C}$, measured by the score of the activity C) and after getting the formative feedback (before the activity D, measured as a score of the activity D). While in the activity $\mathrm{C}$ mean score was 8.4 (out of 12 marks), in the activity D was average score 10.5 (out of 12 marks). Measured by the second set of criteria, we also see a clear qualitative rise, we kept this only on a qualitative base.

As an interesting supplement, we added to our research also semistructured discussion with the students trying to find the retention of the knowledge and will to use this type of activity in their future work - teaching physics at higher secondary school. While at the beginning (activity A) no of the students had experience with similar activity (this had not been implemented in their curriculum at schools where they were secondary school students some years ago), and only $25 \%$ of students were able to present some arguments for such activity, 2 months after the last activity (activity D) 65\% of the students presented, that open inquiry (planning experiment) should be an integral part of the curriculum and that it is important in the development of abilities of teenagers at higher secondary school. 


\section{Discussion}

In Physics of higher secondary education physics experiment have important, sometimes crucial role. Our innovations in physics curriculum are focused on the development of both, empirical and theoretical means of knowledge gathering. Within the development of theoretical methods of cognition of our students, we usually do not forget creativity, critical thinking, judgment, classification, brainstorming, analogy, induction, deduction, abduction, analysis and synthesis, working theory building. Within the development of empirical methods, we do not forget observing, measuring and experiments performing. Most of the implementation of these methods are usually lead by physics teacher instructions. Generally, most of the discussion in the physics class is lead by the structure - initiation (by the teacher), reaction/answer (by a pupil), judgment (by the teacher). It has been proved, that such style of physics teaching does not appropriately develop creativity and critical thinking. Via planning experiments, via open student inquiry, we can see that science of well-being can bring added value to the science education and that we should develop all three character traits, self-directedness, cooperativeness, and self-transcendence. It is not enough to focus on the self-directedness an cooperativeness (as we usually do, leading to the organized character). If we go also to more intuitive and meditative adolescents, identifying with nature and humanity, we help them to be creative. The creative character is driven by interest in coherence and is guided by their intuition to express their potential through self-realization in harmony with others and nature. Creative people are not eccentric for its own sake, because they are steered toward harmony and integration. Within planning of experiments, we also develop the feeling, that a student is a social being. $\mathrm{He} / \mathrm{She}$ is planning, in open inquiry, an experiment answering a question, which is relevant to his/her and also is relevant for others, at least for peers. He/She is working with his/her own ideas, experience (which is social), he/she is working with external sources of information (which are social), he/she is presenting his/her plans to others and is presenting the relevance of the problem and ways how to manage the problem, research question. The Knowledge in Pieces approach helps in deep analysis of progress in building relevance of the improving abilities to plan a sensible processes leading to new knowledge, planning experiment set in a relevant context, utilising students ideas, knowledge, intuition, sense for usefulness.

Deeper bottom-up study based on theoretical knowledge is planned to steer our attention on sensible curriculum relevant for the near future. Still open is the question about technology utilisation in planning experiments. Optimistic results in this way are already presented by some researches, e.g. (Trihn-Ba T., 2016), (Heck, A., 2012). The next generation of our children should be taught a sensible physics content, in a well-designed learning environment, by well-educated teachers with well-developed knowledge, abilities, and relationships. 


\section{Acknowledgement}

Authors are gratteful to the support from the Slovak Research and Development Agency under the contract APVV-14-0070.

\section{References}

Cloninger, C.R. 2013. What makes people healthy, happy, and fulfilled in the face of currewnt world challenges? Mens Sana Monographs, 11 (1) 16-24, doi: 10.4103/09731229.109288

Cloninger, C.R. Personality and temperament: New and alternative perspectives. Focus. 2010;8:161-3.

Cloninger, C.R, Kedia, S. The phylogenesis of human personality: Identifying the precursors of cooperation, altruism, and well-being. In: Sussman, R.W., Cloninger, C.R., editors. The origins of cooperation and altruism. New York: Springer; 2011. pp. 63-110.

Demkanin, P. 2018. Concept Formation: Phsics Teacher ad his Know-how and Know-why. In: Journal of Baltic Science Education, 2018, Volume 17, No.1, p.4-7. ISSN 16483898 Archived at: 〈http://oaji.net/articles/2017/987-1519059651.pdf>

Demkanin, P. 2013. Preparation of physics teachers from various perspectuives. In: Journal of Baltic Science Education, 2013 Volume 12 No.1 p. 4-5. ISSN 1648-3898.

Demkanin, P., Gergel'ová, B. 2017. Development of Aptitude for Team Work via Physics Education. In: Valovičová, L., Ondruška, J. (editor): From the Roots to Contemporary Education - Proceedings of the 20th International Conference DIDFYZ. vyd. New York: AIP Publishing, 2017, ISBN: 978-0-7354-1472-3, doi: 10.1063/1.4974380

Demkanin, P., Velanová, M. 2016. Klúčcové tézy obsahu prírodovedného vzdelávania ako kritérium výberu obsahu pre prírodovedné kurikulum. [Big Ideas as Criteria for selection of content in science curriculum design] In: Held L. (editor) Východiská prípravy prírodovedného kurikula pre základnú školu 2020 II. Trnava: Trnavská Univerzita, p. 21-44. ISBN 978-80-8082-994-0

Demkaninová, D. 2015. Osobnost' v kontexte ADHD [Persionality in the context of ADHD]. In Herényiová, G. ADHD $v$ bio/psycho/sciálnom kontexte. Bratislava. Psychoprof. 
Harlen, W. 2006. Teaching, Learning and Assessing Science 5-12. London: SAGE. ISBN 978-1-4129-0872-6

Heck, A. 2012. Perspectives on an Integrated Computer Learning Environment, Labor Grafimedia Utrecht, ISBN 978-90-804652-0-6

Chalupková, S., Demkanin, P. 2011. Student's hobbies as a context for physics teaching. In: Scientia in Educatione, Vol.2, No.1, p. 15-22. ISSN 1804-7106

IBO, 2014a. MYP Science Guide, International baccalaureate Organisation.

IBO, 2014b. Physics Guide. International Baccalaureta Organisation.

IBO, 2001. Physics Guide, Dilomma programme. International Baccalaureate Organisation.

Krajcik, J., Namsoo, S. 2014. Project-Based Learning in: Sawyer, R.K.(edited by), The Cambridge Handbook of the Learning Sciences, Second Edition, New York: Cambridge University Press, 2014. kap. 14 s. 278-276 ISBN 978-1-107-62657-7

Klentschy, M., \& Thompson, L. 2008. Scaffolding Science Inquiry Through Lesson Design. Vyd. Heinemann, 2008. 144 s. ISBN-13: 978-0325011547

Lieberman, M. 2013. Social: Why Our Brains Are Wired to Connect. Crown.

Machamer, P,. Darden, L., Craver, C. 2000. Thinking about mechanisms. Philosophy of Science, 67, 1-25.

Sawyer, R.K. 2014 The Cambridge Handbook of the Learning Sciences, Second Edition, New York: Cambridge University Press, 2014. ISBN 978-1-107-62657-7

diSessa, A. 2014. The Construction of Causal Schemes: Learning Mechanisms at the Knowledge Level. Cognitive Science 38(5), 795-850. doi:10.1111/cogs.12131

Trihn-Ba T. 2016. Development of course on integration ICT into inquiry-based science education, Vrije Universitat Amsterdam, ISBN: 978-94-92496-00-3

Velmovská. K., Bartošovič, L. 2016. Developing crtitical thinking skills in physics classes. In: Critical thinking: Theories, methods, and challenges. New York: Nova Science Publishing, 2016. s. 21-43. ISBN 978-1634843492 